\title{
On Neighbourhood and Partial Sums of a Certain Subclasses of Analytic Functions with Respect to $\beta$-Symmetric Points
}

Darwish H, Lashin Abd AM and Sowileh S*

Department of Mathematics, Faculty of Science, Mansoura University, Mansoura, Egypt

\begin{abstract}
In the present investigation, we introduce a new class k-Ũ $C^{(\beta)}(\lambda ; \gamma)$ of analytic functions in the open unit disc $U$ with negative coefficients. The object of the present paper is to determine coefficients estimates, neighbourhoods and partial sums for functions $f(z)$ belonging to this class.
\end{abstract}

Keywords: Analytic function; Uniformly starlike function; Quasiconvex functions; Coefficient estimate; Neighbourhood; Partial sums; $\beta$-Symmetric points; 2010 Mathematics subject classification; $30 \mathrm{C} 45$

\section{Introduction}

Let A denote the family of functions $f$ of the form [1]:

$$
f(z)=z+\sum_{n=2}^{\infty} a_{n} z^{n}
$$

that are analytic in the open unit $\operatorname{disc} \mathrm{U}=\{\mathrm{z}:|\mathrm{z}|<1\}$.

For $f \in \mathrm{A}$ given by (1.1) and $\mathrm{g}(\mathrm{z})$ given [2] by:

$$
g(z)=z+\sum_{n=2}^{\infty} d_{n} z^{n}
$$

their convolution (or Hadamard product) denoted by $\left(f^{\star} \mathrm{g}\right)$ is defined [3] as:

$$
\left(f^{*} \mathrm{~g}\right)(z):=z+\sum_{n=2}^{\infty} a_{n} d_{n} z^{n}=:\left(g^{*} f\right)(z)(z \in U)
$$

Let $\mathcal{S} ; \mathcal{K} ; \mathcal{C}$ and $\mathcal{Q C}$ be the usual subclasses [4-7] of A consisting of starlike, convex, close-to-convex and quasi-convex in $\mathcal{U}$, respectively. Thus, by definition, we have [8-15],

$$
\begin{aligned}
& S^{*}=\left\{f: f \in A \text { and } \operatorname{Re}\left\{\frac{z f^{\prime}(z)}{f(z)}\right\}>0(z \in U)\right. \\
& K=\left\{f: f \in A \text { and } \operatorname{Re}\left\{\frac{z f^{\prime \prime}(z)}{f^{\prime}(z)}\right\}>0(z \in U)\right. \\
& C=\left\{f: f \in A \exists g \in S^{*} \text { such that } \operatorname{Re}\left\{\frac{z f^{\prime}(z)}{g(z)}\right\}>0(z \in U)\right. \\
& \text { And } \\
& \mathcal{Q C}=\left\{f: f \in A \exists g \in k \text { such that } \operatorname{Re}\left\{\frac{z f^{\prime}(z)}{g^{\prime}(z)}\right\}>0(z \in U)\right\}
\end{aligned}
$$

Let $S_{S}^{*}$ be the subclass of $S$ consisting of functions of the [16-28] form eqn. (1.1) satisfying:

$$
\operatorname{Re}\left\{\frac{z f^{\prime}(z)}{f(z)-f(-z)}\right\}>0(z \in U)
$$

These functions are called starlike with respect to symmetric points and were introduced by Sakaguchi [19] (see also Robertson [17]; Stankiewicez [25]; Wu [28] and Owa [14]. In El-Ashwah and Thomas [9], introduced and studied two other classes namely the class $S_{S}^{*}$ consisting of functions starlike with respect to conjugate points and $S_{S}^{*}$ consisting of functions [18] starlike with respect to symmetric conjugate points. Recently several subclasses of analytic functions with respect to k-symmetric points were introduced and studied by various authors $[5,16]$.

A function $f \in \mathrm{A}$ is said to be in k- US( $(\gamma)$, the class of k-uniformly starlike functions of order $\gamma ; 0 \leq \gamma<1$; if it satisfies the condition

$$
\operatorname{Re}\left\{\frac{z f^{\prime}(z)}{f(z)}-\gamma\right\}>k\left|\frac{z f^{\prime}(z)}{f(z)}-1\right|(k \geq 0)
$$

and a function $f \in \mathrm{A}$ is said to be $\mathrm{k}$ - $\mathrm{UC}(\gamma)$, the class [19] of k-uniformly convex functions of order $\gamma ; 0 \leq \gamma<1$; if it satisfies the condition:

$$
\operatorname{Re}\left\{1+\frac{z f^{\prime \prime}(z)}{f^{\prime}(z)}-\gamma\right\}>k\left|\frac{z f^{\prime \prime}(z)}{f(z)}\right|(k \geq 0)
$$

Uniformly starlike and uniformly convex functions were [20] first introduced by Goodman [11] and then studied by various authors. It follows from (1.5) and (1.6) that:

$$
f(\mathrm{z}) \in \mathrm{k}-\mathrm{UC}(\gamma) \Leftrightarrow \mathrm{z} f(\mathrm{z}) \in \mathrm{k}-\mathrm{US}(\gamma)
$$

Let $S_{S}^{(\beta)}(\gamma)$ denote the class of functions in A [21] satisfying the following inequality:

$$
\operatorname{Re} \frac{z f^{\prime}(z)}{f_{\beta}(z)}>\gamma(z \in U)
$$

where $0 \leq \gamma<1 ; \beta \geq 2$ is a fixed positive integer and $f_{(\beta)}(z)$ is [22] defined by the following equality:

$$
f_{\beta}(z)=\frac{1}{\beta} \sum_{v=2}^{\beta-1} \epsilon^{-\nu} f\left(\epsilon^{\nu} z\right)(\in=\exp (2 \pi i / \beta, z \in U))
$$

And a function $f(z) \in \mathrm{A}$ is in the class $C_{S}^{(\beta)}(\gamma)$ if and only if $\mathrm{z} f(\mathrm{z}) \in$ $S_{S}^{(\beta)}(\gamma)$ : The classes $S_{S}^{(\beta)}(\gamma)$ of starlike functions with respect to

${ }^{*}$ Corresponding author: Sowileh S, Department of Mathematics, Faculty of Science, Mansoura University, Mansoura, Egypt, Tel: +20502383781; E-mail: s_soileh@yahoo.com

Received April 10, 2018; Accepted April 11, 2018; Published April 15, 2018

Citation: Darwish H, Lashin Abd AM, Sowileh S (2018) On Neighbourhood and Partial Sums of a Certain Subclasses of Analytic Functions with Respect to $\beta$-Symmetric Points. J Appl Computat Math 7: 397. doi: 10.4172/21689679.1000397

Copyright: @ 2018 Darwish H, et al. This is an open-access article distributed under the terms of the Creative Commons Attribution License, which permits unrestricted use, distribution, and reproduction in any medium, provided the original author and source are credited. 
Citation: Darwish H, Lashin Abd AM, Sowileh S (2018) On Neighbourhood and Partial Sums of a Certain Subclasses of Analytic Functions with Respect to $\beta$-Symmetric Points. J Appl Computat Math 7: 397. doi: 10.4172/2168-9679.1000397

$\beta$-symmetric points of order [23] and $C_{S}^{(\beta)}(\gamma)$ of convex functions with respect to $\beta$ - symmetric points of order were considered recently by Singh [4] and Wang et al. [26] respectively. We now introduce and investigate the following subclasses of A with respect [24-28] to $\beta$-symmetric points and obtain some interesting results.

\section{Definition 1.1}

We say that $f \in \mathrm{A}$ belongs to the class $\mathrm{k}-\mathrm{UC}^{(\beta)}(\lambda ; \gamma)$ if for all $\mathrm{z} \in \mathrm{U}$ :

$$
\operatorname{Re}\left\{\frac{z f^{\prime}(z)+\lambda z^{2} f^{\prime \prime}(\mathrm{z})}{(1-\lambda) f_{\beta}(z)+\lambda z f_{\beta}^{\prime \prime}(z)}-\gamma\right\} \geq\left|\frac{z f^{\prime}(z)+\lambda z^{2} f^{\prime \prime}(z)}{(1-\lambda) f_{\beta}(z)+\lambda z f_{\beta}^{\prime}(z)}-1\right|
$$

for $0 \leq \gamma<1,0 \leq \lambda \leq 1$ and $k \geq 0$.

\section{Definition 1.2}

We say that $f \in \mathrm{A}$ belongs to the class $\mathrm{k}-\mathrm{UQC}^{(\beta)}(\lambda ; \gamma)$ if for all $\mathrm{z} \in \mathrm{U}$.

$$
\operatorname{Re}\left\{\frac{z f^{\prime \prime \prime}(z)+(2 \lambda+1) z^{2} f^{\prime \prime}(z)+z f^{\prime}(z)}{\lambda z^{2} f_{\beta}^{\prime \prime}(z)+z f_{\beta}^{\prime}(z)}-\gamma\right\} \geq\left|\frac{\lambda z^{3} f^{\prime \prime \prime}(z)+(2 \lambda+1) z^{2} f^{\prime \prime}(z)+z f^{\prime}(z)}{\lambda z^{2} f_{\beta}^{\prime \prime}(z)+z f_{\beta}^{\prime}(z)}-1\right|
$$

for $0 \leq \gamma<1 ; 0 \leq \gamma \leq 1$ and $\mathrm{k} \geq 0$ :

Denote by $\mathrm{T}$ the subclass of A consisting of functions of the form:

$$
f(z)=z-\sum_{n=2}^{\infty} \epsilon^{-v} a_{n} z^{n} \quad\left(a_{n} \geq 0, n \in \mathbb{N}\right)
$$

For convenience, we write $\mathrm{k}-\mathrm{U} C^{\beta}(\lambda ; \gamma) \cap \mathrm{T}$ simple as $\mathrm{k}-\tilde{\mathrm{U}} \mathrm{C}^{\beta}(\lambda ; \gamma)$; and $\mathrm{k}-\mathrm{UQC}^{\beta}(\lambda ; \gamma) \cap \mathrm{T}$ simple as k- $\mathrm{UQC}^{\beta}(\lambda ; \gamma)$.

\section{Remark 1.1}

(i) For $\mathrm{k}=0$; the classes $\mathrm{k}-\tilde{\mathrm{U}} C^{(\beta)}(\lambda ; \gamma)$ and $\mathrm{k}-\tilde{\mathrm{UQ}} C^{\beta}(\lambda ; \gamma)$ reduce to the classes $C^{(\beta)}(\lambda ; \gamma)$ and $\mathrm{QC}^{(\beta)}(\lambda ; \gamma)$ respectively introduced by Wang et al. [27].

The aim of the present paper to study the coefficient bounds, partial sums and certain neighbourhood results of the classes $\mathrm{k}-\tilde{\mathrm{U}} \mathrm{C}^{(\beta)}(\lambda, \gamma)$ and $\mathrm{k}-\mathrm{UQC}^{(\beta)}(\lambda, \gamma)$. only if

(ii) Coefficient bounds of the function classes $\mathrm{k}-\tilde{\mathrm{U}} \mathrm{C}^{(\beta)}(\lambda, \gamma)$ if and

$$
\sum_{n=2}^{\infty}[1+\lambda(n-1)]\left[n(\mathrm{k}+1)-\mathrm{b}_{n}(k+\gamma)\right] a_{n} \leq 1-\gamma
$$

Where,

$$
b_{n}=\frac{1}{\beta} \sum_{v=0}^{\beta-1} \epsilon^{(n-1) v}=\left\{\begin{array}{ll}
1, & \mathrm{n}=\imath \beta+1 \\
0, & n \neq \imath \beta+1
\end{array}\right\}
$$

The result is sharp for the function $f(z)$ given by:

$$
f(z)=z-\frac{1-\gamma}{[1+\lambda(n-1)]\left[n(\mathrm{k}+1)-\mathrm{b}_{n}(k+\gamma)\right]} z^{n}
$$

Proof:

Assume that the inequality (2.1) holds true. Then we have:

$$
\begin{aligned}
& k\left|\frac{z f^{\prime}(z)+\lambda z^{2} f^{\prime \prime}(z)}{(1-\lambda) f_{\beta}(z)+\lambda z f_{\beta}^{\prime}(z)}-1\right|-\operatorname{Re}\left\{\frac{z f^{\prime}(z)+\lambda z^{2} f^{\prime \prime}(z)}{(1-\lambda) f_{\beta}(z)+\lambda z f_{\beta}^{\prime}(z)}-1\right\} \\
& \leq(1+k)\left|\frac{z f^{\prime}(z)+\lambda z^{2} f^{\prime \prime}(z)}{(1-\lambda) f_{\beta}(z)+\lambda z f_{\beta}^{\prime}(z)}-1\right| \leq \\
& \frac{(1+k) \sum_{n=2}^{\infty}[1+\lambda(n-1)]\left[n-b_{n}\right] a_{n} z^{n-1}}{1-\sum_{n=2}^{\infty}[1+\lambda(n-1)] a_{n} b_{n} z^{n-1}} \leq 1-\gamma
\end{aligned}
$$

Conversely, if $f(z) \in \mathrm{k}-\tilde{\mathrm{U}} \mathrm{C}^{(\beta)}(\lambda ; \gamma)$ and $\mathrm{z}$ is real, then

$$
\frac{1-\sum_{n=2}^{\infty}[1+\lambda(n-1)]\left[n-b_{n}\right] a_{n} z^{n-1}}{1-\sum_{n=2}^{\infty}[1+\lambda(n-1)] a_{n} b_{n} z^{n-1}}-\gamma \geq k\left|\frac{\sum_{n=2}^{\infty}[1+\lambda(n-1)]\left[n-b_{n}\right] a_{n} z^{n-1}}{1-\sum_{n=2}^{\infty}[1+\lambda(n-1)] a_{n} b_{n} z^{n-1}}-1\right|
$$

Letting $\mathrm{z} \rightarrow 1$ - along the real axis, we obtain:

$$
\sum_{n=2}^{\infty}[1+\lambda(n-1)][n(k+1)] a_{n} \leq 1-\gamma
$$

This completes the proof of Theorem 2.1.

\section{Corollary 2.1:}

If $f(\mathrm{z}) \in \mathrm{k}-\tilde{\mathrm{U}} C^{(\beta)}(\lambda ; \gamma)$; then,

$$
a_{n} \leq \frac{1-\lambda}{\left[1+\lambda(n-1)\left[n(k+1)-b_{n}(k+\gamma)\right]\right]},
$$

where $b_{n}$ is defined by (2.2) and $0 \leq \gamma<1,0 \leq \lambda \leq 1 ; \beta \geq 2$; and $k \geq 0$.

\section{Theorem 2.2:}

A function $f(z) \in \mathrm{T}$ is in the class $\mathrm{k}-\tilde{\mathrm{UQQ}} C^{(\beta)}(\lambda ; \gamma)$ if and only if

$$
\sum_{n=2}^{\infty} n[1+\lambda(n-1)]\left[n(k+1)-b_{n}(k+\gamma)\right] a_{n} \leq 1-\gamma
$$

where $b_{n}$ is defined by (2.2), and $0 \leq \gamma<1,0 \leq \lambda<1 ; \beta \geq 2$, and $k \geq 0$ : The result is sharp for the function $f(z)$ given by:

$$
f(z)=z-\frac{1-\gamma}{n[1+\lambda(n-1)]\left[n(k+1)-b_{n}(k+\gamma)\right]}
$$

Proof:

By Denition 1.2, the proof is similar to that of Theorem 2.1.

\section{Neighbourhood of the Function Class k-ŨQC ${ }^{(\beta)}(\lambda ; \gamma)$}

Following the earlier investigations (based upon the familiar concept of neighborhoods of analytic functions) by Goodman [10], Ruscheweyh [18], Altintas et al. [1,2] and others including Srivastava et al. [22,23], Orhan [13], Deniz et al. [7], Catas [3,6], we dene the neighborhood of a function $f \in \mathrm{T}$ by:

\section{Definition 3.1}

Let $01 ; 0 \leq \lambda \leq 1,0 \leq \gamma<1, \mathrm{k} \geq 0, \alpha \geq 0$ and $\mathrm{b}_{\mathrm{n}}$ is dened by (2.2). We define the $a$-neighbourhood of a function $f \in \mathrm{T}$ and denote by $\mathrm{N}_{\alpha}(f)$ consisting of all functions $g(z)=z-\sum_{n=2}^{\infty} d_{n} z^{n} \in S\left(d_{n} \geq 0, n \in \mathbb{N}\right)$
satisfying:

$$
\sum_{n=2}^{\infty} \frac{[1+\lambda(n-1)]\left[n(k+1)-b_{n}(k+\gamma)\right]}{1-\gamma}\left|a_{n}-d_{n}\right| \leq \alpha
$$

\section{Theorem 3.1}

Let $f \in \mathrm{k}-\tilde{\mathrm{U}} \mathrm{C}^{(\beta)}(\lambda ; \gamma)$ and for all real $\theta$ we have $\gamma\left(\mathrm{e}^{\mathrm{i} \theta}-1\right)-2 \mathrm{e}^{\mathrm{i} \theta} \neq 0$ : For and complex number $\in$ with $|\epsilon|<\alpha(\alpha \geq 0)$; if it satisfies the following condition:

$$
\frac{f(z)+\in z}{1+\in} \in k-\tilde{U} C^{(\beta)}(\lambda, \gamma)
$$

then $\mathrm{N}_{\alpha}(f) \subset \mathrm{k}-\tilde{\mathrm{U}} \mathrm{C}^{(\beta)}(\lambda ; \gamma)$

\section{Proof:}

It is easy to see that

$\operatorname{Rew}>\mathrm{k}|\mathrm{w}-1|+\gamma \Leftrightarrow \operatorname{Re}\left\{\mathrm{w}\left(1+\mathrm{ke}^{\mathrm{i} \theta}\right)-\mathrm{ke}^{\mathrm{i} \theta}\right\}>\gamma ;(-\pi<\theta<\pi ; 0 \leq \gamma<1 ; \mathrm{k} \geq 0) ;$ 
By definition 1.1, $\mathrm{f} \in \mathrm{k}-\tilde{\mathrm{U}} \mathrm{C}^{(\beta)}(\gamma, \lambda)$ if and only if

$$
-\operatorname{Re}\left\{\frac{z f^{\prime}(z)+\lambda z^{2} f^{\prime \prime}(z)}{(1-\lambda) f_{\beta}(z)+\lambda z f_{\beta}^{\prime}(z)}-1\right\} \geq k\left|\frac{z f^{\prime}(z)+\lambda z^{2} f^{\prime \prime}(z)}{(1-\lambda) f_{\beta}(z)+\lambda z f_{\beta}^{\prime}(z)}-1\right|
$$

the above inequality may be rewritten as follows:

$$
\operatorname{Re}\left\{\frac{z f^{\prime}(z)+\lambda z^{2} f^{\prime \prime}(z)}{(1-\lambda) f_{\beta}(z)+\lambda z f_{\beta}^{\prime}(z)}\left(1+\mathrm{ke}^{\mathrm{i} \theta}\right)-\mathrm{ke}^{\mathrm{i} \theta} \succ \gamma\right\}
$$

or equivalently,

$$
\operatorname{Re}\left\{\frac{z f^{\prime}(z)+\lambda z^{2} f^{\prime \prime}(z)\left(1+\mathrm{ke}^{\mathrm{i} \theta}\right)-\mathrm{ke}^{\mathrm{i} \theta}\left[(1-\lambda) \mathrm{f}_{\beta}+\lambda z f_{\beta}^{\prime}(z)\right]}{(1-\lambda) f_{\beta}(z)+\lambda z f_{\beta}^{\prime}(z)} \succ \gamma\right\}
$$

Now, by setting

$$
F(z)=\left[z f^{\prime}(z)+\gamma z^{2} f^{\prime \prime}(" z)\right]\left(1+k e^{i \theta}\right)-k e^{i \theta}\left[[1-\lambda] f_{\beta}(z)+\lambda z f_{\beta}^{\prime}(z)+\lambda z f_{\beta}^{\prime}(z)\right](3.4)
$$

And

$$
E(z)=(1-\lambda) f_{\beta}(z)+\lambda z f_{\beta}^{\prime}(z)
$$

the inequality (3.3) becomes equivalent to

$$
|F(z)+(1-\gamma) E(z)|>|F(z)-(1+\gamma) E(z)| \text { for } 0 \leq \gamma<1
$$

Then

$$
\left|\frac{\left[z f^{\prime}(z)+\lambda z^{2} f^{\prime \prime}(z)\left(1+\mathrm{ke}^{\mathrm{i} \theta}\right)-\mathrm{ke}^{\mathrm{i} \theta}\left[(1-\lambda) \mathrm{f}_{\beta}+\lambda z f_{\beta}^{\prime}(z)\right]\right]}{z f^{\prime}(z)+\lambda z^{2} f^{\prime \prime}(z)\left(1+\mathrm{ke}^{\mathrm{i} \theta}\right)-\mathrm{ke}^{\mathrm{i} \theta}\left[(1-\lambda) \mathrm{f}_{\beta}+\lambda z f_{\beta}^{\prime}(z)\right]}\right|<1
$$

$(-\pi<\theta<\pi)$; for any complex number s with $|s|=1$, we have

$$
\left|\frac{\left[z f^{\prime}(z)+\lambda z^{2} f^{\prime \prime}(z)\left(1+\mathrm{ke}^{\mathrm{i} \theta}\right)-\mathrm{ke}^{\mathrm{i} \theta}\left[(1-\lambda) \mathrm{f}_{\beta}+\lambda z f_{\beta}^{\prime}(z)\right]\right]}{z f^{\prime}(z)+\lambda z^{2} f^{\prime \prime}(z)\left(1+\mathrm{ke}^{\mathrm{i} \theta}\right)-\mathrm{ke}^{\mathrm{i} \theta}\left[(1-\lambda) \mathrm{f}_{\beta}+\lambda z f_{\beta}^{\prime}(z)\right]}\right| \neq s
$$

which is equivalent to

$$
\frac{\left(f^{*} h\right)(z)}{z} \neq 0 \quad(z \in U)
$$

Where

$$
h(z)=z-\sum_{n=2}^{\infty} c_{n} z^{n}
$$

$C_{n}:=\frac{[1+\lambda(n-1)]\left[n-b_{n}\left(1+k e^{i \theta}-s k e^{i \theta}\right)-s\left(n+b_{n}\right)-b_{n} \gamma(1-s)\right]}{\gamma(s-1)-2 s}$

It follows from (3.7) that

$\left|C_{n}\right|:=\frac{[1+\lambda(n-1)]\left[n-b_{n}\left(1+k e^{i \theta}-s k e^{i \theta}\right)-s\left(n+b_{n}\right)-b_{n} \gamma(1-s)\right]}{\gamma(s-1)-2 s} \leq \frac{[1+\lambda(n-1)]\left[n(1+k)-(k-\gamma) b_{n}\right]}{1-\lambda}$

If $f(\mathrm{z}) \in \mathrm{k}-\tilde{\mathrm{U}} \mathrm{C}^{(\beta)}(\lambda, \gamma)$ given by (1.9), satisfies the inclusion property (3.1), then (3.6) yields

$$
\left|\frac{f(z)^{*} h(z)}{z}\right| \geq \alpha \quad(\mathrm{z} \in \mathbb{U})
$$

Now, if we suppose that

$$
g(z)=z-\sum_{n=2}^{\infty} d_{n} z^{n} \in N_{\alpha}(f)
$$

We easily see that

$$
\begin{aligned}
\left|\frac{(g-f)(z)^{*} h(z)}{z}\right| & =\left|\sum_{n=2}^{\infty}\left(d_{n}-a_{n}\right) c_{n} z^{n}\right| \\
& \leq \sum_{n=2}^{\infty}\left|d_{n}-a_{n}\right|\left|c_{n}\right||z|^{n} \\
& \leq \sum_{n=2}^{\infty} \frac{[1+\lambda(n-1)]\left[n(1+k)-b_{n}(k-\gamma)\right]}{1-\gamma}\left|a_{n}-d_{n}\right| \leq \alpha
\end{aligned}
$$

Then,

$$
\begin{aligned}
\left|\frac{(g)(z) * h(z)}{z}\right| & =\left|\frac{(f+(g-f)(z) * h(z))}{z}\right| \\
& \geq\left|\frac{f(z) * h(z)}{z}\right|-\left|\frac{(g-f)(z) * h(z)}{z}\right|>0
\end{aligned}
$$

Thus, for any complex number s such that $|s|=1$, we have

$$
\frac{(g)(z) * h(z)}{z} \neq 0
$$

which implies that $\mathrm{g}(\mathrm{z}) \in \mathrm{k}-\tilde{\mathrm{U}} \mathrm{C}^{(\beta)}(\lambda, \gamma)$ so $\mathrm{N}_{\mathrm{a}}(f) \subset \mathrm{k}-\tilde{\mathrm{U}} \mathrm{C}^{(\beta)}(\lambda, \gamma)$.

\section{Partial Sums of the Function Class K-Ũ ${ }^{(B)}(\lambda, \gamma)$}

In this section, applying methods used by Silverman [20] and Silvia [21], We investigate the ratio of the real part of $f(z)$ which dened by (1.9) to its sequence of partial sums dened by $f_{1}(z)=z$ and

$$
f_{m}(z)=z-\sum_{n=2}^{\infty} a_{n} z^{n} \quad(m \in \mathbb{N}) .
$$

\section{Theorem 4.1:}

If $\mathrm{f}(\mathrm{z}) \in \mathrm{k}-\tilde{\mathrm{U}} \mathrm{C}^{(\beta)}(\lambda, \gamma)$ then

$\operatorname{Re}\left\{\frac{f(z)}{f_{m}(z)}\right\} \geq 1-\frac{1}{1+\delta_{m+1}} \quad(z \in U, m \in \mathbb{N})$

And

$\operatorname{Re}\left\{\frac{f_{m}(z)}{f(z)}\right\} \geq \frac{\delta_{m+1}}{1+\delta_{m+1}} \quad(z \in U, m \in \mathbb{N})$

Where

$$
\delta_{n}=\frac{\left[1+\lambda(n-1)[n(1+k)]-(\mathrm{k}+\gamma) \mathrm{b}_{n}\right]}{1-\gamma}
$$

The bounds in (4.1) and (4.2) are the best possible for each $\mathrm{m} 2 \mathrm{~N}$. Proof. We employ the same technique used by Silverman [20]: The function $f(\mathrm{z}) \in \mathrm{k}-\tilde{\mathrm{U}} \mathrm{C}^{(\beta)}(\lambda, \gamma)$, If and only if $\sum_{n=2}^{\infty} \delta_{n} a_{n} \leq 1$. It is not difficult
to verify that $\delta_{\mathrm{n}+1}>\delta_{\mathrm{n}}>1[29]$.

$$
\sum_{n=2}^{\infty} a_{n}+\delta_{m+1} \quad \sum_{n=m+1}^{\infty} a_{n} \leq \sum_{n=2}^{\infty} \delta_{n} a_{n} \leq 1
$$

We may write

$$
\begin{aligned}
& \frac{1+w(z)}{1-w(z)}=\delta_{m+1}\left\{\frac{f(z)}{f_{m}(z)}-\left(1-\frac{1}{\delta_{m+1}}\right)\right. \\
& =\left\{\frac{1-\sum_{n=2}^{m} a_{n} z^{n-1}-\delta_{m+1} \sum_{n=m+1}^{\infty} a_{n} z^{n-1}}{1-\sum_{n=2}^{m} a_{n} z^{n-1}}\right\}
\end{aligned}
$$


Citation: Darwish H, Lashin Abd AM, Sowileh S (2018) On Neighbourhood and Partial Sums of a Certain Subclasses of Analytic Functions with Respect to $\beta$-Symmetric Points. J Appl Computat Math 7: 397. doi: 10.4172/2168-9679.1000397

Page 4 of 5

Then, from (4.5) we can obtain,

$$
w(z)=\frac{-\delta_{m+1} \sum_{n=2}^{m} a_{n} z^{n-1}}{2-2 \sum_{n=2}^{m} a_{n} z^{n-1}-\delta_{m+1} \sum_{n=m+1}^{\infty} a_{n} z^{n-1}}
$$

And

$$
|w(z)| \leq \frac{-\delta_{m+1} \sum_{n=m+1}^{m} a_{n}}{2-2 \sum_{n=2}^{m} a_{n} z^{n-1}-\delta_{m+1} \sum_{n=m+1}^{\infty} a_{n}}
$$

Now $|\mathrm{w}(\mathrm{z})| \leq 1$ if and only if

$$
\sum_{n=2}^{m} a_{n}+\delta_{m+1} \sum_{n=m+1}^{m} a_{n} \leq 1
$$

which is true by (4.4). This readily yields the assertion (4.1) of Theorem 4.1. To see that:

$$
f(z)=z-\frac{z^{m+1}}{\delta_{m+1}}
$$

gives sharp results, we observe that for $\mathrm{z}=\gamma \mathrm{e}^{\mathrm{i} \pi / \mathrm{m}}$

$$
\frac{f(z)}{f_{m}(z)}=1-\frac{z^{m}}{\delta_{m+1}} \rightarrow 1-\frac{1}{\delta_{m+1}} \text { as } z \rightarrow 1^{-}
$$

Similarly, we take

$$
\frac{1+w(z)}{1-w(z)}=\left(1+\delta_{m+1}\right)\left\{\frac{f_{m}(z)}{f(z)}-\frac{\delta_{m+1}}{1+\delta_{m+1}}\right\},
$$

Where

$$
|w(z)| \leq \frac{\delta_{m+1} \sum_{n=m+1}^{m} a_{n}}{2-2 \sum_{n=2}^{m} a_{n}-\delta_{m+1} \sum_{n=m+1}^{\infty} a_{n}} \leq 1
$$

Now $|w(z)| \leq 1$ if and only if,

$$
\sum_{n=2}^{m} a_{n}+\delta_{m+1} \sum_{n=m+1}^{m} a_{n} \leq 1
$$

which is true by (4.4). This immediately leads to the assertion (4.2) of Theorem 4.1. The estimate in (4.2) is sharp with the extremal function $\mathrm{f}(\mathrm{z})$ given by (4.6). This completes the proof of Theorem 4.1.

\section{Theorem 4.2:}

If $f(\mathrm{z}) \in \mathrm{k}-\tilde{\mathrm{U}} C^{(\beta)}(\lambda, \gamma)$ then,

$$
\begin{aligned}
& \operatorname{Re}\left\{\frac{f^{\prime}(z)}{f^{\prime}(z)}\right\} \geq 1-\frac{m+1}{\delta_{m+1}}, \quad(z \in U, m \in \mathbb{N}) \\
& \operatorname{Re}\left\{\frac{f_{m}^{\prime}(z)}{f^{\prime}(z)}\right\} \geq 1-\frac{\delta_{m+1}}{1+m+\delta_{m+1}}, \quad(z \in U, m \in \mathbb{N})
\end{aligned}
$$

The estimates in (4.7) and (4.8) are sharp with the extremal function given by (4.6).

Proof: The proof is similar to that of Theorem 4.1.

\section{References}

1. Altintas O, Owa S (1996) Neighbourhoods of certain analytic functions with negative coefficients. Int J Math Sci 19: 797-800.

2. Altintaş O, Özkan Ő, Srivastava HM (2000) Neighbourhoods of a class of analytic functions with negative coefficients. Appl Math Lett 13: 63-67.

3. Catas A (2009) Neighbourhoods of a certain class of analytic functions with negative coefficients. Banach J Math Anal 3: 111-121.

4. Chand R, Singh P (1979) On certain schlicht mappings. Indian J Pure Appl Math 10: 1167-1174.

5. Darwish HE, Lashin AY, Sowileh SM (2017) Some properties for $\alpha$-star like functions with respect to $k$-symmetric points of complex order. Ann Univ Marie Curie-Sklodowska 71: 1-9.

6. Darwish HE, Lashin AY, Soileh SM (2013) An application of multiplier transformation for certain subclasses of meromorphic $p$-valent functions. Int $J$ Pure Appl Math 85: 45-433.

7. Deniz E, Orhan H (2010) Some properties of certain subclasses of analytic functions with negative coefficients by using generalized Ruscheweyh derivative operator. Czechoslovak Math J 60: 699-713.

8. Duren PL (1983) Univalent functions. Springer-Verlag 1: 983.

9. El-Ashwah RM, Thomas DK (1987) Some subclasses of close-to-convex functions. J Ramanujan Math Soc 2: 85-100.

10. Goodman AW (1957) Univalent functions and nonanalytic curves. Proc Amer Math Soc 8: 598-601.

11. Goodman AW (1991) On uniformly starlike functions. J Math Anal Appl 155 364-370.

12. Noor KI (1987) On quasi-convex functions and related topics. J Math Math Sci 10: $241-258$

13. Orhan $\mathrm{H}$ (2007) On neighbourhoods of analytic functions defined by using Hadamard product. Novi Sad J Math 37: 17-25.

14. Owa S, Wu Z, Ren F (1988) A note on certain subclass of Sakaguchi functions. Bull Soc Roy Sci Liège 57: 143-149.

15. Owa S, Nunokawa M, Saitoh H, Srivastava HM (2002) Close-to-convexity, starlikeness, and convexity of certain analytic functions. Appl Math Lett 15: 63-69.

16. Ramachandran C, Kavitha D, Soupramanien T (2015) Certain Bound forStarlike and-Convex Functions with respect to Symmetric Points. Inter J Math Math Sci, p: 7.

17. Robertson MS (1961) Applications of the subordination principle to univalent functions. Pacic J Math 11: 315-324.

18. Ruscheweyh $S$ (1981) Neighbourhoods of univalent functions. Proc Amer Math Soc 81: 521-527.

19. Sakaguchi K (1959) On a certain univalent mapping. J Math Soc Japan 11: 72-75.

20. Silverman $\mathrm{H}$ (1997) Partial sums of starlike and convex functions. J Math Anal Appl 209: 221-227.

21. Silvia EM (1985) On partial sums of convex functions of order. Houston J Math 11: 397-404.

22. Srivastava HM, Aouf MK (1992) A certain fractional derivative operator and its applications to a new class of analytic and multivalent functions with negative coefficients I. J Math Anal Appl 171: 1-13.

23. Srivastava HM Aouf MK (1992) A certain fractional derivative operator and its applications to a new class of analytic and multivalent functions with negative coefficients II. J Math Anal Appl 192: 673-688.

24. Srivastava HM, Owa S (1989) Univalent functions, fractional calculus, and their applications. Halsted Press.

25. Srivastava HM, Owa S (1992) Current topics in analytic function theory. World Scientific.

26. Stankiewicz J (1965) Some remarks on functions starlike with respect to symmetric points. Ann Univ Mariae Curie-Skłodowska Sect A 19: 53-59.

27. Wang ZG, Gao CY, Yuan SM (2006) On certain subclasses of close-to-convex and quasi-convex functions with respect to k-symmetric points. J Math Ana Appl 322: 97-106. 
Citation: Darwish H, Lashin Abd AM, Sowileh S (2018) On Neighbourhood and Partial Sums of a Certain Subclasses of Analytic Functions with Respect to $\beta$-Symmetric Points. J Appl Computat Math 7: 397. doi: 10.4172/2168-9679.1000397

Page 5 of 5

28. Wang ZG, Gao CY, Orhan H, Akbulut S (2007) Some subclasses of close-toconvex and quasi-convex functions with respect to k-symmetric points. General Math 15: 107-119.
29. Wu Z (1987) On Classes of Sakaguchi functions and Hadamard products. Sci Sinica Ser 30: 128-135 